\title{
Modelling rainfall intensity from NOAA AVHRR data for operational flood forecasting in Malaysia
}

\begin{abstract}
Many empirical studies in numerical weather prediction have been carried out that establish the relationship between top-of-the-cloud brightness temperature and rainfall particularly in tropical and equatorial regions of the world. Malaysia is a tropical country that lies along the path of the north-east and south-west monsoon rainfall, which sometimes causes extensive flood disasters. Observations have generally shown that heavy cumulonimbus cloud formation and thunderstorms precede the usual heavy monsoon rains that cause flood disasters in the region. In this study, a model has been developed to process National Oceanic \& Atmospheric Administration Advanced Very High Resolution Radiometer (AVHRR) satellite data for rainfall intensity in an attempt to improve quantitative precipitation forecasting (QPF) as input to operational hydro-meteorological flood early warning. The thermal bands in the multispectral AVHRR data were processed for brightness temperature. Data were further processed to determine cloud height and classification performed to delineate clouds in three broad classes of low, middle, and high. A rainfall intensity of 3-12 $\mathrm{mm}$ h-1 was assigned to the 1-D cloud model to determine the maximum rain rate as a function of maximum cloud height and minimum cloud model temperature at a threshold level of $235 \mathrm{~K}$. The result of establishing the rainfall intensity based on top of the cloud brightness temperature was very promising. It also showed a good areal coverage that delineated areas likely to receive intense rainfall on a regional scale. With a spatial resolution of $1.1 \mathrm{~km}$, data are course but provide a good coverage for an average river catchment/basin. This raises the opportunity of simulating rainfall runoff for the river catchment through the coupling of a suitable hydro-dynamic model and GIS to provide early warning prior to the actual rainfall event.
\end{abstract}

